directly or indirectly with 1,200 schools, and whilst a big programmo of conversion from gas lighting to electric lighting has taken place, the conversion to electric heating, with the exception of reflector fires in open-air schools, has been slow. The standard adopted for the lighting of schools is 8-10 footcandles. Mr. Jackson points out that the low ceilings now favoured in modern schools make totally indirect lighting of class rooms undesirable, for a low ceiling when too bright has a depressing effect. It is known that the all-electric housing experiments of the L.C.C., of the St. Pancras Housing Association and others have been great successes. During the last four years, 23,000 houses or flats have been converted from gas to electric lighting by the L.C.C. More than 80 per cent of the tenants had electric light installed although their rent was raised to meet the cost of wiring.

\section{Preventing Oil Fires in Power Stations}

A STUDy of the inflammation of lubricating and similar oils recently mado in the research laboratories of Messrs. Mather and Platt, Ltd., Park Works, Manchester, has elucidated the mode of combustion of these oils and led to the development of the 'Mulsifyre' system of extinguishing oil fires (Beama Journal of June). It was found that when lubricating oil was heated in a container to the temperature commonly employed with modern steam turbines, the oil does not take fire. The danger arises when there is a relatively thin film of the oil falling on, or flowing over, a steam pipe. As the oil flows over the hot surface, the complex molecules are 'cracked' and new substances are formed. The heavier fractions remain clinging to the metal surface, while the lighter fractions volatilize. Between these volatilized fractions and the oxygen of the atmosphere an exothermic reaction takes place causing a considerable increase of temperature, and now substances appear, aldehydes, acetic acid, bituminous matter and saponifiablo oil.

IT was found that whilst the open flash point of the oil used was greater than $400^{\circ} \mathrm{F}$., the flash point of the volatile fractions was only about $175^{\circ} \mathrm{F}$. When ignition takes place in these circumstances it never does so at a point in contact with the steam pipe. The flame can often be seen to develop in the air several inches above the pipe. In order that the oil spurting from a defective pipe joint may catch fire, it must be sprayed in the air in a finely divided form. The underlying principle of the 'Mulsifyre' system of quenching oil fires is to change the nature of the liquid. By emulsifying it, the inflammable liquid becomes incapable of burning. With the 'Aulsifyre', the mechanical agitation is provided by discharging water under pressure through a special form of nozzle on to the surface of the oil. The water, issuing from this projector in a strong, driving, well distributed spray, it strikes the oil with considerable force. The projectors are effective either when quite close to the oil or when many feet away from it. A large-scale demonstration plant has been erected at Park Works, Manchester.

\section{The Universal Decimal Classification}

Mavy classifications have been evolved rather as an intellectual exercise than with any specific aim in view. Others have been made in the attempt to devise a so-called logical system. Irost have lapsed already into obscurity. The success of the Decimal Classification, which has survived sixty years of test and is still being adopted at an increasing rate, is a testimony to the qualities inherent in its structure and order. No alternative has been found to be sufficiently valuable to justify detailed development to the extent which the Dewey Classification has experienced, and no classification which lacks such detailed expansion is capable of replacing the Universal Decimal Classification. This classification was adopted unanimously as the international standard classification by representatives of more than forty Governments at the World Congress of Universal Documentation held in Paris in 1937. The Classification is employed in thousands of institutions throughout the world for the indexing and arrangement of public and private archives, books, references to published articles in literature and documents and apparatus of all kinds. Some 150,000 published references to literature in the field of science and technology alone are classified annually in accordance with this code, besides many hundreds of thousands of items in private files. The total work will com. prise about 2,000 pages of printing in double column, including about 70,000 classos, and costing about $£ 6$. The appearance of "Section 51, Chemistry" (London : Messrs. Simpkin and Marshall, 1939. 7s. 6d.) will be welcomed by all those concerned with the progress of bibliography. The new Section comprises puro and theoretical chemistry. The industrial processes for the manufacture, of chemicals will appear as Section 66. The present section contains about 4,000 main clauses, capable of dealing, in the minutest detail, with every aspect of modern chemistry; as an example of its application may bo mentioned the Royal Dutch Petroleum Company, which utilizes the classification to index annually some 120,000 items, mainly of chemical interest.

\section{Evolution of the University Clinic and its Laboratories}

Two lectures were delivered by Prof. Simon Flexner at Oxford early in the present year, in which he traced the establishment of clinics in medicine and surgery on a university basis. $\mathrm{He}$ suggested that this involves three factors: (1) the provision of laboratories in the clinic for scientific research, (2) tho appointment of clinical professors qualified in at least one subject of medical research, and (3) the power of these professors to command time for the patients from whom the research problems are derived. The key to the achievement of these conditions, Prof. Flexner considers, lies in laboratories attached to the clinics, where investigator and student meet and labour together, and he proceeded to review the history of the development of such laboratories. The establish. ment of clinical laboratories was traced back to John Hughes Bennett and Lionel Smith Beale in tho 